\title{
MODERATION BY RESEARCHGATE RELATED TO COMMENTS ON "PREDATORY" PUBLISHING PRACTICES
}

\author{
Panagiotis Tsigaris ${ }^{7}$, \\ Jaime A. Teixeira da Silva²
}

\begin{abstract}
The intersection between academia and social media is gradually overlapping. The ability to vent personal and professional discord online, either through blogs or social media, has had both positive and negative consequences on academic communication, with the public and/or in the public domain. ResearchGate $(R G)$ is one of the most popular academic social media sites that allows commenting, either in response to published papers or to questions that are posed on that platform. This paper explores an important aspect of a high-profile, topical and controversial 2017 paper (Derek Pyne; Journal of Scholarly Publishing; DOI: 10.3138/jsp.48.3.137) that had based itself on a flawed blacklist created by Jeffrey Beall. In that paper, unfounded claims were made regarding financial rewards as remuneration schemes at a "small business school" in Canada related to publishing papers in "predatory" journals, i.e., in open access journals that were blacklisted by Beall. Based on those claims, Pyne used RG as a platform to target academics at his research institute. Pyne could have, but did not, use the scholarly platform to engage with his colleagues in an academic debate about his controversial findings, causing personal disrepute on three occasions. Consequently, RG was contacted with a claim of defamation on each occasion. Within hours of each claim, Pyne's comments were deleted. In early May, RG also erased his social media account. The issue of actual or potential insults in the public domain, such as on blogs, is rarely discussed, much less related to academic social media sites like RG. This case study, and the issues discussed herein related to social media more broadly, will be useful for academics to better navigate increasingly challenging publishing waters.
\end{abstract}

Keywords: ethical research; invalid claims; Jeffrey Beall's blacklists; ResearchGate; research spin.

\section{An ungrounded claim of rewards for Beall-blacklisted publications}

"Predatory" publishing, which involves unfair and/or unscholarly exploratory behavior, is not only a hot topic in academic publishing. It is a real threat to academia's integ-

805 TRU Way, Department of Economics, Thompson Rivers University, Kamloops, British Columbia, V2C 0c8, Canada; ptsigaris@tru.ca

2 P. O. Box 7, Miki-cho post office, Ikenobe 3011-2, Kagawa-ken, 761-0799, Japan; jaimetex@ yahoo.com 
rity, and is not limited to open access (OA). Jeffrey Beall's blacklists, one for OA journals and another for OA publishers, became both famous and infamous. We focus on the latter in this case study, because the fundamental flaws, opacity and potential false positives associated with Beall's blacklists (Teixeira da Silva and Tsigaris, 2018a) spurred others to, consciously or not, use such lists to incorrectly characterize and mislabel other academics.

This case study focuses on a paper by Derek Pyne, an Associate Professor at Thompson Rivers University (TRU) ${ }^{3}$, in Canada. Pyne (2017) published a paper in the Journal of Scholarly Publishing (JSP; University of Toronto Press) that claimed that research faculty members in a "small business school" were financially rewarded for having published in "predatory" journals, i.e., in OA journals and publishers that were blacklisted by Beall. That claim was unfounded, not only because Beall's blacklists might carry a high false discovery rate (Teixeira da Silva and Tsigaris, 2018a), thereby invalidating any interpretation or analysis based on those lists, but mainly because the claim of financial rewards for such publications was not supported by his own evidence in the published paper (Tsigaris, 2019). Pyne attempted unsuccessfully to associate Beall-blacklisted journal publications, mostly from the blacklist of publishers, with overload income in the belief that faculty who published in such journals had more time to take on more teaching loads and make extra income. Pyne also claimed that $15.3 \%$ of publications by members of the business school were "predatory", a claim which we refute in Tsigaris and Teixeira da Silva (2019), showing that the values are bloated, and depend on the blacklist that is used, while the conclusions drawn are highly subjective. Unsuccessful in finding evidence of such financial rewards, but claiming otherwise, signs of interpretive bias (also known as research spin) was present for an alternative version of the evidence in the abstract and elsewhere (Boutron and Ravaud, 2018; Finn, 2019; Khan et al., 2019), including in the media (Teixeira da Silva and Tsigaris, 2019). The aim was to persuade readers that the university was complicit in financially rewarding "predatory" publishing at the "small business school" in Canada when the evidence clearly showed non-significant results (Turrentine, 2017). Once published in the journal, Pyne suddenly decided to reveal the exact location where the study took place on April 5th 2017 in the newspaper OttawaCitizen entitled: "Are Universities complicit in predatory publishing?"4

As a direct result of Pyne's study, and the ensuing trail of unsubstantiated claims made in mainstream media and on social media, the reputation of the "small business school", which is a respected Canadian academic institute of higher tertiary education, has now been imperiled. ${ }^{5}$ Whereas the institute and subjects of these unsupported claims were previously unknown to the public, Pyne revealed the identity of the institute through numerous media reports, and a simple Google search using "Derek Pyne" and "Thompson Rivers University" will confirm several of these facts. Any disclosure of

\footnotetext{
3 http://kamino.tru.ca/experts/home/main/bio.html?id=dpyne

4 Even though there were enough indirect identifiers in the paper, Pyne kept the anonymity of the location of his human subject to that of a "small business school in Canada" but post publication the media frenzy of false accusations started with the op-ed he wrote in the Ottawa Citizen immediately after publication: https://ottawacitizen.com/opinion/columnists/pyne-are-universities-complicit-in-predatory-publishing

For example, the Chronicle of Higher Education, which is widely read by numerous academics and university administrators, entitled a blog post "Does It Pay to Be Published in 'Predatory' Journals?" states: "A recent study of one university's business school, however, found that many of its professors had repeatedly published in journals with such reputations, and actually appear to have improved their pay and prestige by doing so. [...] Mr. Pyne concludes in an article on his findings in last month's Journal of Scholarly Publishing. [...], and publication in such journals was positively correlated with income." Income was not positively correlated with Beall's list of publications. In fact, Table 5 of Pyne's study shows the opposite, i.e., that these publications were negatively correlated with salary. Why did Pyne not correct this misrepresentation of his findings?
} 
the subject(s) of that study namely the institute or academics therein, and which were purportedly anonymous, or revealing their identities, would thus constitute a serious infringement of privacy. Such disclosures and revelations would constitute the following violations: 1 ) violation of the claims of anonymity made in the paper $\left.{ }^{6} ; 2\right)$ violation of the publication ethics and malpractice policies of the publisher of JSP, University of Toronto (UoT) Press ${ }^{7}$; 3) potential ex post violation of the agreement signed between Pyne and UoT Press. ${ }^{8}$ The privacy and confidentiality of human subjects used in research is a fundamental right protected by Canadian human rights laws. ${ }^{9}$

\section{What is the position of the journal, Journal of Scholarly Publishing?}

The journal that published the Pyne study, i.e., JSP, was contacted in June of 2018 with a formal call to retract the flawed Pyne study. A retraction was requested precisely because Pyne used that study to make unsupported claims, and to compromise the anonymity of the human subjects used in the study. JSP rejected the possibility of a retraction but allowed Tsigaris to write a letter to the editors critiquing the study (Tsigaris, 2019). The journal rarely publishes letters to the editors and no reply to the letter from Pyne was published. We believe JSP wanted to close this issue, truncating any possible communication by any member of Canadian or global academia that questions or challenges the Pyne study. Why does JSP not allow academics' freedom of expression to challenge academic findings in its own journal beyond the letter to the editors by Tsigaris? ${ }^{10}$ Legitimate academic challenge and criticism of a journal's content within the

$6 \quad$ For example, Pyne did not title the paper: "The Rewards of predatory publications at Thompson Rivers University" but titled it as "The Rewards of predatory publications at a small business school" and throughout the paper he did not mention that the study took place at Thompson Rivers University. We are uncertain if this was due to an editorial decision or due to Pyne trying to maintain anonymity of the location until it was accepted for publication

$7 \quad$ For publication ethics of the UoT Press see: https://www. utpjournals.press/resources/publication-ethics. In particular the following bullet applies to patients but can be applicable to any human subject used in a study: "Ensure patients' rights to privacy when publishing articles involving human subjects. UTP encourages journals to follow the ICMJE guidelines for reporting on human subjects. For articles containing detailed information about a living patient, it is necessary for signed patient consent to be obtained. Any identifying characteristics that might reveal a patient's identity must be removed (i.e., x-rays, MRIs, charts, photographs, etc.). Written informed consent is also needed from any potentially identifiable patient or that patient's legal representative. This consent should be presented in the submission." Pyne did not seek consent from the human subjects and was exempted from a research ethics review.

$8 \quad$ Pyne has agreed to point 4 of the University of Toronto Press' author's agreement for journal publications, which states: https://utpjournals.press/pb-assets/utoronto/UTPJournalsContract-1463708041193.pdf: "The Author(s) further warrant that the article contains no defamatory or otherwise unlawful matter and that it makes no improper invasion of the privacy or personal rights of anyone. The Author(s) undertake that all statements in it purporting to be facts are true; and that they will advise us of any statements that might be construed as defamatory or otherwise unlawful. We may require substantive revision of the manuscript to avoid including material that may infringe rights or be defamatory or otherwise unlawful."

$9 \quad$ Chapter 12 of the Tri-Council Policy Statement: Ethical Conduct for Research Involving Humans with application to human biomedical material states: "There is widespread agreement about the interests of participants in protection of privacy, and the corresponding duties of researchers to treat personal information in a confidential manner. Indeed, the respect for privacy in research is an internationally recognized norm and ethical standard. Fundamental rights and freedoms in the Canadian Constitution have been interpreted by the courts to include privacy protections. Privacy rights are protected in federal and provincial/territorial legislation." The right to protect a person's privacy and personal information is not only covered by the Canadian Constitution but also by British Columbia's Personal Protection information act, Chapter 63. See: http://www.bclaws.ca/EPLibraries/ bclaws_new/document/ID/freeside/00_03063_01

10 Incidentally, both this paper and the Tsigaris and Teixeira da Silva (2019) papers had initially 
same journal or elsewhere is fundamental to the advancement of knowledge and should not be avoided or terminated. It is editors' responsibility to provide a platform for authors challenging a journal paper's findings (Teixeira da Silva and Dobránszki, 2018).

\section{ResearchGate used as a platform by Pyne to belittle individuals}

It is within a ResearchGate (RG) campaign that Pyne made comments to demean individuals. Leaving aside the fact that all researchers employed at the small business school in Canada can be identified because of the multiple revelations of the location of his study, raising ethical issues on the privacy and confidentiality of the human subjects, Pyne publicly - via RG - named some individuals used in his study, while others can be uniquely identified. We next discuss these occurrences.

\section{First occurrence}

In response to a question by Deborah Poff at $R G$ as to whether predatory publishing equals presenting at WCRI, on February 13, 2019, Pyne made the following claim: "This question has come up before on ResearchGate. I firmly believe that as long as there is a demand for their services, predatory publishers will exist. There will be a demand for their services as long as some universities continue to count them as real publications. My own university is one that does count them as real publications (at least in some faculties like the business school). If the universities in question are publicly funded, I think that the government may have a role to pay in changing their behavior. BTW, Deborah Poff I see you are with Carleton. I actually wrote something in the Ottawa Citizen about this https://ottawacitizen.com/opinion/columnists/pyne-are-universities-complicit-in-predatory-publishing."11 Deborah Poff, who is editor-in-chief of Journal of Academic Ethics, co-series editor of Advances in Business Ethics Research and a co-founding editor of the Journal of Business Ethics ${ }^{12}$, all published by Springer Nature, replied "Thanks Derek". To set the record straight, Panagiotis Tsigaris sent a personal message to Deborah Poff about Pyne's unfounded claims and providing a link to his letter. Seeing that Poff did not reply to Tsigaris' message, he decided to post the message as a comment responding to Pyne's statement that his University is complicit in rewarding predatory publications. On February 22, Tsigaris made the comment public, which still appears on RG, stating: "Deborah Poff, Pyne's claim of the existence of financial compensation for Beall's publications is false. ${ }^{13}$ The study did not find the university under study to be complicit in rewarding Beall's journal publications or as a matter of fact any other type of publication. See: http://muse.jhu.edu/article/716980." (Fig. 1A). Most likely Pyne got upset as seen from his reply: "Peter, I realize having a history of predatory publishing, you feel defensive. However, I will respond when the time and place is right." Pyne once again, without any evidence other than Beall's flawed OA publishers list, classified his colleague Tsigaris as having a "history of publishing in predatory journals" instead of discussing and debating the letter by Tsigaris. ${ }^{14}$ However, this statement, in conjunction with identification of the location where the study took place, clearly identifies Tsigaris as a subject of the Pyne (2017) study. Tsigaris can thus be seen by researchers as publishing in bogus-type journals and getting financial rewards for such publications, which is untrue. Tsigaris imme-

\footnotetext{
been submitted to JSP, which refused to consider them for peer review.

11 https://www.researchgate.net/post/Predatory_publishing_presenting_at_WCRI

12 http://www.wcri2019.org/index/programme/plenary_speakers (Poff is a plenary speaker at the 6th World Conference on Research Integrity)

13 It is false because the JSP study suffers from methodological, statistical and interpretative errors (Tsigaris, 2019).

14 According to Cabell's blacklist and Crawford's Gray OA list, Tsigaris does not have questionable journal publications. Background in Tsigaris and Teixeira da Silva (2019).
} 
diately issued a formal claim of defamation to RG. ${ }^{15}$ Tsigaris used a Supreme Court of Canada case of defamation between Grant v. Torstar Corp., 2009 SCC 61, [2009] 3 and in particular paragraph [28] to show proof of defamation. First, "that the impugned words were defamatory...". Second, "that the words in fact referred to the plaintiff". Third, "that the words were published..." It was noted also that the tort is one of strict liability. ${ }^{16}$ RG analyzed the comment and complaint, and removed the comment on February 28, 2019 (see Fig. 1A). ${ }^{17}$ By our best estimates, the comment was visible to the public for at least 5 days, i.e., the comment had given a negative public image to TRU and its academics, specifically Tsigaris. No new comments have been posted on that Poff question site since February 2, 2019. ${ }^{18}$

Figure 1 Evidence of removal of first comment (A) and third comment (B) following claims of defamation to ResearchGate (RG; Appendix 1) made by Tsigaris. Second comment is not shown since TRU academics' names are displayed. (C) Derek Pyne's RG account (https://www. researchgate.net/profile/Derek_Pyne2) was disabled and now simply is redirected to the RG profiles page. Screenshot of $C$ taken on March 13, 2019. Pyne's RG account is not archived on the internet archive (https://archive.org/web/).

A February 25,2019

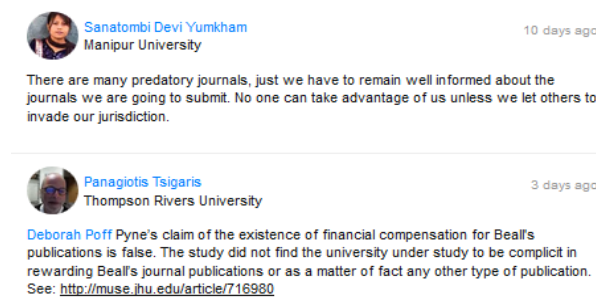

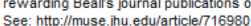

February 28, 2019

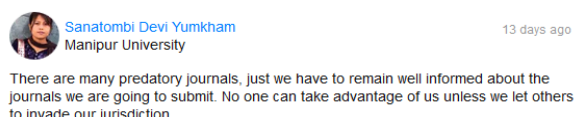

There are many predatory journals, just we have to remain well informed about the
journals we are going to submit. No one can take advantage of us unless we let others to invade our jurisdiction

Panagiotis Tsigaris

Deborah Poff Pyne's claim of the existence of financial compensation for Beall's publications is false. The study did not find the university under study to be complicit in rewarding Bealls sournal publications or as a matter or

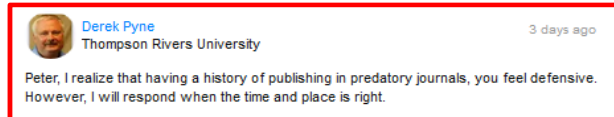

Comment removed by ResearchGate. However, I will respond when the time and place is right:

B

$$
\begin{aligned}
& \text { Derek Pyne } \\
& \text { Thompson Rivers University }
\end{aligned}
$$

Thompson Rivers University predatory publications and do so because they are rewarded for them. For example, this year's promotions, four of the six people to get promoted at the business school a was given to someone with predatory publications numbering in the double digits. For more information on the rewards involved, see Article The Rewards of Predatory Publications at a Small Business School We even had a "research mentor" with six predatory publications

Comment removed by ResearchGate.

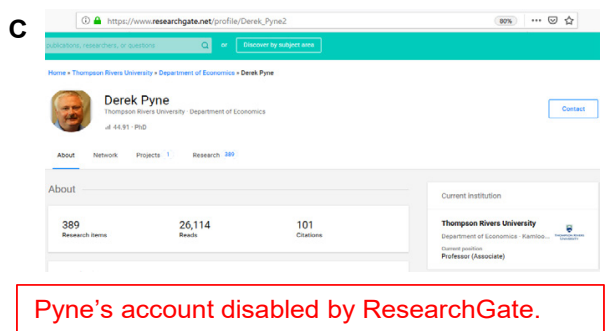

\section{Second occurrence}

In early April 2019, Pyne added another personal mischaracterization of Tsigaris

\footnotetext{
15 Details are available upon request. See Appendix 1 for the front page of the notice of claimed defamation

16 See: https://scc-csc.lexum.com/scc-csc/scc-csc/en/item/7837/index.do

17 RG informed Tsigaris of the removal of the comment in an email.

18 Tsigaris had admitted via emails to his school in the past that he had published papers in Beall's list of potential predatory publishers. However, most of the publications were published before Beall blacklisted the publishers and prior to being aware of the flaws associated with Beall's blacklists. Tsigaris has no publications with publishers in Cabell's blacklist (https://www2.cabells.com/ about-blacklist)
} 
to another page on RG because the Tsigaris' JSP letter to the editors cast doubt about Pyne's claim of the university being complicit in rewarding "predatory" publications. ${ }^{19}$ Tsigaris felt that the motivation behind this outburst again was to harm his reputation, to "lower him in the estimation of right thinking members of society generally", to expose him to "potentially public hatred, contempt or ridicule", and to cause him to be "shunned and avoided", as is stated in the RG notice of claimed defamation form. This time, the "attack" went further by listing Tsigaris' six publications, including the names of his co-authors which were data used in the published JSP study. Pyne again claimed they were predatory publications simply because the publishers were listed in Beall's blacklist of potentially, probable, possible predatory OA publishers. He also claimed that Tsigaris lacks knowledge. ${ }^{20}$ In addition, to the personal attack publicly on RG, Pyne undermined the process of promotion at TRU. He claimed that four out of six individuals who got promoted this year (in 2019) have "predatory" publications. Was this done to imply publicly that they did not deserve promotion? Since the four individuals can be uniquely identified and all are RG members, Pyne may have harmed their reputation as academics. Pyne also questioned the TRU award for excellence in research and scholarship just because that faculty member had publications in journals published by publishers on Beall's blacklist. Tsigaris submitted a second notice of claimed defamation to RG who removed the comment immediately and informed Tsigaris of the removal.

\section{Third occurrence}

There was a third and final comment placed by Pyne on RG on April 4, 2019 (Fig. 1B). This time there were no explicit names mentioned in the comment. However, he again claimed that faculty who got promoted and the person who received the TRU research award had "predatory" publications, further stating that a "research mentor" had six predatory publications, most likely aiming at Tsigaris' academic record since Tsigaris has mentored many junior faculty and students. Since Pyne's comment identified the location and the publicly available events in 2019 (i.e., a promotion at TRU School of Business Economics and the TRU research award), all individuals can be uniquely identified. Tsigaris decided this time not to reply with a comment linking it to his JSP letter to the editors as in the other two cases but instead submitted a third notice of claimed defamation on April 15, 2019. RG immediately removed this third comment and informed Tsigaris of the removal in an email.

\section{Concluding remarks}

Sometime in May, 2019, the authors noticed that Pyne's RG profile has been disabled (Fig. 1C). Moreover, all his comments dating back for at least two years could no longer be traced. No explanation appears on the RG website and no notice of this change was sent to Tsigaris. RG does have a number of challenges associated with its platform, for example the project function (Teixeira da Silva, 2017), the RG Score (Copiello, 2019), Research Interest (Copiello and Bonifaci 2019), and other issues that have been discussed under the section "Criticisms" on Wikipedia ${ }^{21}$. In this case, however, we believe that $R G$ has done the right thing.

\section{Conflicts of interest}

The authors declare no conflicts of interest, financial or otherwise, of relevance to this topic.

\footnotetext{
19 https://www.researchgate.net/post/Can_we_protect_our_youth_scientists_against_questionable_publishers

20 For privacy issues, we are withholding evidence of the comments. These may be made available upon reasonable request as a confidential document, but applications will be carefully screened 21 https://en.wikipedia.org/wiki/ResearchGate
} 


\section{Disclaimer}

Both authors have published papers in OA journals or in journals by OA publishers that were blacklisted by Beall. Such publications should be accurately recorded on an academic's curriculum vitae, but not separately to other non-blacklisted publishing sources, simply because all publications should merit the same attention, or scrutiny (Teixeira da Silva and Tsigaris, 2018b).

\section{References:}

BOUTRON, I., RAVAUD, P. (2018) Misrepresentation and distortion of research in biomedical literature. Proceedings of the National Academy of Sciences USA 115(11): 2613-2619. DOI: 10.1073/pnas. 1710755115

COPIELLO, S. (2019) Research Interest: another undisclosed (and redundant) algorithm by ResearchGate. Scientometrics (in press). DOI: 10.1007/s11192-019-03124-w

COPIELLO, S., BONIFACI, P. (2019) ResearchGate Score, full-text research items, and full-text reads: a follow-up study. Scientometrics 119: 1255-1262. DOI: 10.1007/s11192-019-03063-6

FIHN, S.D. (2019). Combating misrepresentation of research findings. JAMA Network Open 2(5): e192553-e192553. DOI: 10.1001/jamanetworkopen.2019.2553

KHAN, M.S., LATEEF, N., SIDDIQI, T.J., REHMAN, K.A., ALNAIMAT, S., KHAN, S.U., RIAZ, H., MURAD, H., MANDROLA, J., DOUKKY, R., KRASUSKI, R.A. (2019) Level and prevalence of spin in published cardiovascular randomized clinical trial reports with statistically nonsignificant primary outcomes: a systematic review. JAMA Network Open 2(5): e192622-e192622. DOI: 10.1001/jamanetworkopen.2019.2622

PYNE, D. (2017) The rewards of predatory publishing at a small business school. Journal of Scholarly Publishing 48(3): 137-160. DOI: 10.3138/jsp.48.3.137

TEIXEIRA DA SILVA, J.A. (2017) ResearchGate projects: unregulated academic social media. Social Communication 1(15): 6-13. DOl: 10.1515/sc-2017-0001

TEIXEIRA DA SILVA, J.A., DOBRÁNSZKI, J. (2018) Editors moving forward: stick to academic basics, maximize transparency and respect, and enforce the rules. Recenti Progressi in Medicina 109(5): 263-266. D0l: 10.1701/2902.29244

TEIXEIRA DA SILVA, J.A., \& TSIGARIS, P. (2018a) What value do whitelists and blacklists have in academia? The Journal of Academic Librarianship 44(6): 781-792. DOI: 10.1016/j.acalib.2018.09.017

TEIXEIRA DA SILVA, J.A, \& TSIGARIS, P. (2018b). Academics must list all publications on their CV. KOME 6(1): 94-99. DOI: 10.17646/KOME.2018.16

TEIXEIRA DA SILVA, J.A, \& TSIGARIS, P. (2019). How hyped media and misleading editorials can influence impressions about Beall's lists of "predatory" publications. Journal of Information, Communication \& Ethics in Society (in press) DOI: 10.1108/JICES-06-2018-0059

TSIGARIS, P. (2019). Letter to the editors. Journal of Scholarly Publishing 50(2): 139-142. DOI: 10.3138/ jsp.50.2.05

TSIGARIS, P., TEIXEIRA DA SILVA, J.A. (2019) Did the research faculty at a small Canadian business school publish in "predatory" venues? This depends on the publishing blacklist. Publications 7: 35. DOI: 10.3390/publications 7020035

TURRENTINE, M. (2017) It's all how you "spin" it: interpretive bias in research findings in the obstetrics and gynecology literature. Obstetrics \& Gynecology 129(2): 239-242. 


\section{Appendix 1: ResearchGate Notice of Claimed Defamation}

"ResearchGate is a platform that enables users to post content and interact with each other. We do not review or edit content posted by users, and have no control over the truth or accuracy of that content. We generally support freedom of expression, but also respect any laws that might apply to particular types of content, including the laws of defamation.

If you are using this form to report content, you should ensure that the content you identify is, in fact, defamatory under the laws of your country. Defamation laws vary from country to country, but generally speaking defamation is a false statement of fact which is deemed to harm the reputation of another. This means it tends to "lower him in the estimation of right thinking members of society generally," or exposes him to public hatred, contempt or ridicule, or causes him to be shunned or avoided.

Not all statements that a person may find objectionable are defamatory. For example, a statement which is true usually will not be defamatory. Similarly, a statement of opinion without reference to facts probably is not defamatory. Defamation is a complex area of the law and you should carefully evaluate any claim before you make it, as making false claims could potentially expose you to liability. It may be wise to consult a lawyer.

In some cases, uploaders willingly remove content. We encourage you to contact the uploader of the content in the first instance, if possible. If you are unable to resolve your issue with the uploader directly, and you wish to request that we remove the content, it is ResearchGate's policy that you submit a Notice of Claimed Defamation. This is, in part, so the alleged false and defamatory content can be clearly identified. For us to be able to process your request, your claim needs to be specific and strongly supported. For example, it needs to explain why you believe the statement(s) is untrue and how it damages your reputation.

If you wish to submit a Notice of Claimed Defamation please complete the form below and email it, with any attachments, to copyright@researchgate.net. To make and save your changes to this form, download it and then open it in Adobe Acrobat Reader DC (you can download Adobe free here: https://get.adobe.com/reader/). Please note that ResearchGate will only consider Notices of Claimed Defamation submitted by the person identified in the content in question or their authorized legal representative." 